\title{
Por uma nova epistemologia do ensino de filosofia no ensino médio: mediações sobre o cotidiano em wittgenstein e em deleuze
}

Fábio Antonio Gabriel ${ }^{1}$ Ana Lúcia Pereira Baccon² Mauricio Silva Alves ${ }^{3}$ Tatiane Skeika ${ }^{4}$

\section{RESUMO:}

O presente trabalho tem como escopo a análise do cenário educacional do Brasil, com ênfase na formação do professor de filosofia do Ensino Médio. O ato de ensinar Filosofia requer um deslocamento epistemológico, a saber: o exercício de reconsideração do cotidiano como categoria filosófica, isto é, a capacidade subjetiva de abertura para novas situações, novos mundos até então banidos do discurso epistemológico inerente à docência, e consequentemente deslocar os docentes do polo de suas certezas epistemológicas - que propõe a receita dogmática de percurso dos caminhos certos para uma aula de filosofia - para o polo do aluno do ensino médio que está indisponível para a filosofia. Nesta perspectiva, o discente do curso de Licenciatura em Filosofia deve ter clareza de que, na sala de aula, em seu lócus de exercício da profissão, tão só o amontoado de teorias e proposições didáticas não será suficiente para a contribuição de um aprendizado eficaz do seu futuro alunado. E também, o conhecimento pedagógico não deve separar-se do conhecimento filosófico, mas complementar um ao outro no cotidiano do professor de filosofia. O campo problemático, aberto pelo cotidiano como categoria filosófica em Wittgenstein e Deleuze, exige uma investigação que nos leva ao sentido por ele produzido. Apresenta-se, desse modo, um paradoxo: o sujeito faz uso de suas experiências passadas tanto para produzir quanto para organizar os acontecimentos mediante uma relação de causa e efeito que não logra conter todo o universo do cotidiano, condição necessária para uma experiência temporal adequada, isto é, uma experiência que traga para quem a exercita, uma simultaneidade de tempos para a produção de sentidos. O sentido é, dessa forma, o próprio acontecimento expresso, é o resultado do que é produzido pelo rompimento do senso comum, das proposições metafísicas, obrigando a uma nova significação do possível, ou seja, do cotidiano como acontecimento, que abre a história e a epistemologia sugando tudo para que gire em torno de si, gerando desse modo uma nova maneira de Ensinar a Filosofia.

\section{PALAVRAS-CHAVE:}

filosofia, Wittgenstein, Deleuze

\footnotetext{
1 Mestre e doutorando em Educação pela Universidade Estadual de Ponta Grossa, professor da Rede Estadual do Paraná de Filosofia, bolsista da Fundação Araucária convênio CAPES. Email: fabioantoniogabriel@gmail.com

2 Doutora em Ensino de Ciências e Educação Matemática pela Universidade Estadual de Londrina. Professora adjunta do Departamento de Matemática e Estatística e no Programa de Mestrado e Doutorado em Educação na UEPG. Bolsista da CAPES - Brasil. Email: ana.baccon@hotmail.com

3 Mestre em Filosofia pela PUC-PR e Professor Substituto de Filosofia e Ensino na Universidade Estadual de Feira de Santana- UEFS-BA.

4 Doutoranda em Educação pela Universidade Estadual de Ponta Grossa, Professora da rede Estadual do Paraná, bolsista CAPES
} 


\title{
autêntica
}

\begin{abstract}
:
The present work has as scope the analysis of the educational scenario of Brazil, with emphasis on the formation of the professor of philosophy of High School. The act of teaching Philosophy requires an epistemological shift, namely: the exercise of reconsideration of everyday life as a philosophical category, that is, the subjective capacity for openness to new situations, new worlds hitherto banished from the epistemological discourse inherent in teaching, and consequently displacing The teachers of the pole of their epistemological certainties - that proposes the dogmatic prescription of the route of the right paths for a philosophy class - to the pole of the student of the high school that is unavailable for the philosophy. In this perspective, the student of the course in Philosophy must have clarity that in the classroom, at the juncture of his profession, only the heap of didactic theories and propositions will not suffice for the contribution of an effective learning of the Their future. And also, the pedagogical knowledge should not be separated from the philosophical knowledge, but complementary to each other in the daily life of the professor of philosophy. The problematic field, open to everyday life as a philosophical category in Wittgenstein and Deleuze, requires an investigation that leads us to the meaning it produces. A paradox is thus presented: the subject makes use of his past experiences both to produce and to organize events through a cause and effect relationship that fails to contain the whole universe of daily life, a necessary condition for adequate temporal experience , That is, an experience that brings to those who exercise it, a simultaneity of times for the production of meanings. Meaning, then, is the expressed event itself; it is the result of what is produced by the breaking of common sense, of metaphysical propositions, forcing a new signification of the possible, that is, every day as an event, which opens history and The epistemology sucking everything so that it revolves around itself, thus generating a new way of Teaching Philosophy.
\end{abstract}

\section{KEYWORDS:}

Philosophy, Wittgenstein, Deleuze 


\section{autêntica}

É importante, para mim, ir modificando a minha postura ao filosofar, não permanecer muito tempo sobre a mesma perna, para não ficar perro. Wittgenstein,( RM).

É importante para mim ir modificando a minha postura ao filosofar, não permanecer muito tempo sobre a mesma perna, para não ficar perro. Wittgenstein ( RM, p. 118)

Atualmente Brasil tem passado por diversas crises, não só no contexto político ou econômico, mas também nos contextos educacionais. Dentre elas, está a discussão do Projeto de Lei sobre "escola sem partido" e a segunda que é sobre a Medida Provisória que ameaçava a retirada das disciplinas de Filosofia, Sociologia, Educação Física e Educação Artística, como disciplinas obrigatórias do currículo, tornando-as como disciplinas optativas. Medida que gerou muitas discussões, debates, manifestações populares e que depois de muito desgaste, recentemente, a Câmara de deputados, volta a trás e aprova novamente a exigência de Filosofia e Sociologia no Ensino Médio. Estar diante da ameaça de retirada da obrigatoriedade do ensino da Filosofia do currículo do Ensino Médio brasileiro, f provocou muitas discussões e reflexões acerca da formação do professor, visto que muitos discentes dos cursos de Filosofia ficaram sem saber de fato qual seria o seu futuro em relação a possibilidade de atuarem em sala de aula e poder viver diversas possibilidades que o ato de ensinar/aprender proporciona.

Nesse sentindo, Zeichner, 1993, destaca que que os formadores de professor tem um papel importantíssimo no desenvolvimento profissional dos futuros professores pois:

Têm obrigação de ajudar os futuros professores a interiorizarem, durante a formação inicial, a disposição e a capacidade de estudarem a maneira como ensinam e de melhorarem, com o tempo, responsabilizando-se pelo seu próprio desenvolvimento profissional (p.17).

$\mathrm{Na}$ atual conjuntura formativa dos cursos de Licenciatura em Filosofia, existe uma preocupação recorrente por parte dos professores: Qual a metodologia adequada para transmitir os conteúdos de Filosofia? Qual a maneira mais eficaz para se realizar de maneira eficaz a "transposição didática" dos conteúdos de Filosofia no ensino médio? De outra maneira, contudo, mostra, de forma menos perceptível, o discente que será professor de Filosofia e que deveria estar disposto a refletir sobre os textos bem como exercitar discussões filosóficas. Há uma crença, mesmo desenhada pelas sutilezas dos equívocos, de que existe um modelo ideal de subjetividade a ser seguido e colocado como paradigma epistemológico do ensino da Filosofia para que se chegue ao saber verdadeiro. Não obstante, a proposição: "tornar o aluno consciente e autônomo" se apresenta nos objetivos dos estagiários como um norte "diretivo" do processo de ensinar filosofia.

A experiência docente no Ensino Médio, de certo modo, exige que se identifique, que se compreenda e que se problematize a realidade multifacetada que é o processo de ensinar/aprender, evidenciando: a dificuldade de ensinar àquele que muitas vezes não está interessado em ouvir; ensinar a um sujeito que muitas vezes não se sente motivado a aprender, ou não está disponível para pensar o que lhe é apresentado nas questões filosóficas. Tais problemas desembocam na possibilidade indicada e fundamentada no ambiente universitário, a saber: a formação alicerçada no monólogo do professor, em que o aluno é apenas ouvinte, e, consequentemente, desconsidera o cotidiano como categoria filosófica no contexto da sala de aula. Tal epistemologia adotada como estrutura formativa para os professores de Filosofia cerceia a esse professor

5 A sigla RM utilizada na citação é uma abreviação da de Wittgenstein: Remarques Mêlées [no original Vermischte Bemerkungen]. Editado por G.H. von Wright. Tradução, apresentação e notas Gérard Granel e JeanPierre Cometti. Paris: Flammarion, 2002. Em português: Cultura e Valor. 


\section{autêntica}

a predisposição de ousar e de apostar em possíveis conexões de ensino que cumpram as demandas atuais do ensino de filosofia da contemporaneidade.

Dois pontos pertinentes podem decorrer acerca da formação de um professor de Filosofia:

o ato de ensinar requer um exercício de reconsideração do cotidiano como categoria filosófica, isto é, a capacidade subjetiva de abertura para novas situações, novos mundos até então banidos do discurso epistemológico inerente à docência;

este ponto diz respeito ao fato de se deslocar os docentes do polo de suas certezas epistemológicas - as quais tiveram sua origem e fundamentação na metodologia de ensino não filosófica, que propõe a receita dogmática de percurso dos caminhos certos para uma aula de filosofia - para o polo do aluno do ensino médio que está indisponível para a filosofia.

Para uma problematização da proposição: "ensinar a pensar", um tanto desgastadas nos objetivos de muitos professores de Filosofia, tomando como base a perspectiva lançada por Wittgenstein de que "a filosofia é um trabalho sobre si mesmo" (RM,p.71), parece urgente a necessidade de se buscar a construção de novas possibilidades para a formação do professor de Filosofia. Essa ideia se apresenta como um contraponto ao modelo sustentado em determinadas práxis epistemológicas centradas em habilidades e em competências e na aplicabilidade de métodos que entendam a linearidade e a previsibilidade dos sujeitos que ensinam e aqueles que aprendem.

Para uma melhor compreensão de como o processo formativo do professor de Filosofia pode ser pensado, com base na perspectiva de reconsideração do cotidiano e do deslocamento de certezas epistemológicas direcionadas para o polo do aluno que não está indisponível para a Filosofia e da problematização da proposição: "ensinar a pensar", Severino propõe que:

Trata-se, então, de levar esses adolescentes a experienciarem essa atividade reflexiva de compartilhamento desse processo de construção de conceitos e valores, experiência eminentemente pessoal e subjetivada, mas que precisa ser suscitada, alimentada, sustentada, provocada, instigada. Eis aí o desafio didático com que nos deparamos (2004, p. 108).

Procuraremos, portanto, pensar, norteados por esses contrapontos, pois, o maior desafio daqueles que formam os professores de filosofia é provocar uma reflexão sobre o ato de ensinar aos alunos do ensino médio a pensarem filosoficamente.

\section{O CONHECIMENTO PEDAGÓGICO SEPARA-SE DA EPISTEMOLOGIA DO DOCENTE DE FILOSOFIA?}

Pensar a profissão docente significa atrelar ao desenvolvimento desse ofício um corpus de saberes que têm como escopo a aprendizagem do outro. "O conhecimento inerente à profissão do professor não está atrelado ao domínio de conteúdos e técnicas". (MORAES, 2003, p.160). Na mesma perspectiva, o discente do curso de Licenciatura em Filosofia deve ter clareza de que, na sala de aula, em seu lócus de exercício da profissão, tão só o amontoado de teorias e proposições didáticas não será suficiente para a contribuição de um aprendizado eficaz do seu futuro alunado. Da mesma maneira: "Considerar o ensino uma atividade natural significa não valorizar a profissão de professor bem como a dimensão universitária de sua formação" (NÓVOA, 2013). 


\section{autêntica}

Desse modo, pensar a profissão docente do professor de Filosofia é entender a existência da necessidade, além dos quesitos inerentes ao contexto de trabalho que compõe o exercício da profissão, um conjunto de saberes pertinentes ao ensinar Filosofia. Nesse viés, é importante considerar a existência de uma base epistemológica específica para o ensino de filosofia, a saber: O despertar da capacidade reflexiva do aluno, como propõem as Orientações Educacionais Complementares aos Parâmetros Curriculares Nacionais (2013) ao tratarem da "representação e comunicação", defendem que, em primeira instância, o professor de Filosofia deve despertar no aluno a reflexão e a problematização, ou seja, o ensinar filosofia filosofando por meio da "análise interpretativa" (BRASIL, 2013, p. 47). Chauí (2009) justifica a epistemologia do professor de Filosofia imbricada à leitura e domínio dos textos filosóficos, e, que somente a leitura dos clássicos possibilita a compreensão primeira dos discursos proferidos pelos filósofos em suas obras, e é partir desse pressuposto que pode haver ensino de filosofia no Ensino Médio.

Porque a filosofia é um discurso dotado de características próprias, a iniciação a ela encontra um caminho seguro no ensino da leitura dessa modalidade de discurso, a fim de que os alunos aprendam a descobrir, no movimento e na ordenação das ideias de um texto, a lógica que sustenta a palavra filosófica para que possam analisá-la e comentá-la, primeiro, e interpretá-la, depois (CHAUÍ, 2009, p. 12).

A leitura e o domínio dos textos filosóficos constituem o ser docente de Filosofia, e se impõem como saberes específicos que devem fundamentar e diferenciar o professor de Filosofia dos demais profissionais. Da mesma forma, dos PCNS de 2006 partem do pressuposto de que existe uma base de conhecimento específico para o ensino de Filosofia no Ensino Médio, e que tal base deve ser pautada pelos textos filosóficos. Constituem, assim, o ser professor de Filosofia:

(...) Tenha feito sua escolha categorial e axiológica, a partir da qual se lê e entende o mundo, pensa e ensina. Caso contrário, além de esvaziar sua credibilidade como professor de Filosofia, faltar-lhe-á um padrão, um fundamento, a partir do qual possa encetar qualquer esboço de crítica. Por certo, há filosofias mais ou menos críticas. No entanto, independentemente da posição que tome (pressupondo que se responsabilize teórica e praticamente por ela), ele só pode pretender ver bons frutos de seu trabalho docente na justa medida do rigor com que operar a partir de sua escolha filosófica - um rigor que, certamente, varia de acordo com o grau de formação cultural de cada um 2006, p. 48).

O quesito: conhecimento filosófico deve constituir a especificidade do fazer pedagógico do professor de Filosofia, fator esse que o diferencia dos demais profissionais. Compreende-se que "os conhecimentos pedagógicos em um curso de Licenciatura em Filosofia são essenciais, mas devem ser conectados ao conhecimento filosófico, a fim de que esses mesmos saberes "originem um sentimento de pertença a um determinado grupo", como bem apresenta Ciampa $(1985$, p.14). Partindo dessa ideia, a formação do professor de Filosofia pode desenvolver uma importante configuração da nova identidade do docente de Filosofia, ao propiciar bases epistemológicas para sua práxis.

A perspectiva de Lee Shulman $(1986,1987,1997)$ atrela a formação docente a um conjunto de conhecimentos, isto é, a uma base epistemológica específica, o que tem contribuído para a elaboração de questões sobre a práxis dos professores e suas possíveis aplicabilidades em sua formação. As ideias de Shulman apontam para "a investigação do conhecimento dos professores em relação aos conteúdos específicos de sua área de formação, e a forma como tais conteúdos são transformados no ensino" (1986, p.4-14). Shulman se interessa pelo esclarecimento da compreensão cognitiva dos conteúdos das disciplinas específicas a serem trabalhadas no cotidiano escolar e suas relações entre os conteúdos ofertados pelos professores aos alunos. 


\section{autêntica}

O "Knowledge" do professor, ou base de conhecimento, ou, ainda, epistemologia do docente para Shulman, significa um "conjunto de compreensões acerca do conhecimento, habilidades e disposições que os docentes adquirem para atuar em determinada área de ensino, tendo como objetivo a identificação do conjunto epistemológico do ensino" (1987, p. 1-14). Desde a década de 80, época em que surgiu essa expressão, ainda não se esgotaram as inúmeras pesquisas que se fundamentam nesse referencial. Tal fundamentação se deve à ideia de que "a relação entre epistemologia e práxis do professor é essencial e encontram-se engendradas uma na outra" (SHULMAN, 1997, p.8).

Desse modo, a formação do professor de Filosofia deve privilegiar a epistemologia docente, e alude ao pensamento de que está atrelado ao conhecimento em sua mais profunda identidade e desenvolvimento profissional; pois, "priorizar o conhecimento docente é valorizar a profissão de professor" (NÓVOA, 2013, p. 199-200). Dessa maneira, pensar o ser professor de Filosofia, nessa especificidade da construção de uma epistemologia entrelaçada à práxis pedagógica, acena para a busca não só do prestígio profissional, mas para uma compreensão de que ser professor de Filosofia no ensino médio pauta-se por um conjunto de conhecimentos filosóficos e pedagógicos, a fim de dirimir a confusão apregoada pelo senso comum de que, para ser professor de Filosofia necessita-se apenas de um profissional dotado de notório saber, isto é, basta ter certa afinidade com a filosofia, ou, mesmo, a falsa concepção de que a filosofia é uma virtude ou dom que permite o exercício da profissão.

Nesse contexto, evidencia-se a problemática de que os professores de Filosofia no Ensino Médio, pautados pela pretensa habilidade de notório saber, encontram dificuldades para dialogar com os alunos, pois não há uma fórmula pedagógica para o ensino e para o aprendizado da disciplina. Diante dessa realidade, aos docentes licenciados em Filosofia esse diálogo torna-se ainda mais espinhoso, dada a particularidade do discurso filosófico e seu desconhecimento ou desinteresse por parte dos alunos, que, em muitos casos, só conheceriam a disciplina de acordo com um profissional dotado de notório saber.

De um lado, há professores de Filosofia desprovidos de uma abordagem sistemática da Filosofia; do outro, profissionais licenciados preocupados em oferecerem uma Filosofia mais acessível e interessante aos alunos por meio do cotidiano, mas essa valorização do ordinário não pode incorrer em atitudes espontaneístas, caracterizadas por expressões, como: " O que vocês querem discutir na aula de hoje?" Tal expressão emana de um docente desprovido de uma proposta de trabalho e que resulta na concepção de que a Filosofia não tem especificidade. Mesmo em atividades pedagógicas com objetivo de atingir o cotidiano dos alunos, recorrendo a textos jornalísticos, filmes, músicas, poesias, seminários temáticos, olimpíadas de filosofia, enquetes, produção de vídeos com temas de seus interesses, e outros temas afins, se tais atividades não estiverem pautadas no estudo de textos filosóficos devidamente estudados e discutidos com os alunos, resultam na dessacralização da Filosofia e, consequentemente, na banalização do cotidiano.

Para que o cotidiano contribua como uma categoria a ser aplicada no ensino de filosofia para o ensino médio, é imprescindível a compreensão do seu significado filosófico (o que inclui, nesse caso, a reflexão acerca da existência da função mediadora do professor entre o cotidiano e o filosofar).

A reflexão acerca do cotidiano como categoria filosófica não pode se limitar à lógica inerente a uma estrutura de pensamento que serve a objetivos prático-utilitários, ou, ainda, a um resultado como de efeito imediato na vida humana. Torna-se oportuno o estudo da estrutura e do pensamento inerentes ao cotidiano, bem como de seus limites e possibilidades. No caso do presente artigo, fazem-se oportunas as concepções filosóficas de Wittgenstein e de Deleuze acerca do cotidiano. 


\section{autêntica}

\section{O COTIDIANO COMO CATEGORIA FILOSÓFICA EM WITTGENSTEIN E EM DELEUZE}

Não seria forçosa a aproximação entre Wittgenstein e Deleuze, já que são autores que estudaram o cotidiano como tema filosófico, tema esse que pode ser traduzido como um acontecimento carregado de sentido, e, é, por esse motivo, a ausência de um sentido, em meio àquilo que já existe, que o acontecimento exige um sentido, obrigando, assim, o sujeito a buscar novos significados para dar conta do que acontece a ele.

O campo problemático aberto pelo cotidiano como categoria filosófica exige uma investigação que nos leva ao sentido por ele produzido. Apresenta-se, desse modo, um paradoxo: o sujeito faz uso de suas experiências passadas tanto para produzir quanto para organizar os acontecimentos mediante uma relação de causa e efeito que não logra conter todo o universo do cotidiano, condição necessária para uma experiência temporal adequada, isto é, uma experiência que traga para quem a exercita, uma simultaneidade de tempos para a produção de sentidos. Dessa forma, o cotidiano, como categoria filosófica em Wittgenstein e Deleuze, deve ser pensado como uma cadeia temporal originada da contraefetuação do sujeito, que, ao ser atingido, busca outras formas, outras expressões para amenizar o paradoxo surgido.

O acontecimento se propaga graças ao funcionamento potente de uma onda de sentidos atribuídos ao paradoxo, que vão se delineando, graças às várias mediações encontradas pelo caminho. O acontecimento, visto desse modo, rompe o discurso decorrido de uma vivência comum, e sua contraefetuação busca reorganizar a experiência no ordinário.

Concorre para essa reorganização a linguagem, tal como disposta na obra Investigações Filosóficas, em que Wittgenstein retoma a linguagem como experiência, mesmo com distinção em primeira pessoa dos enunciados sobre como a manifestação de estados interiores, a expressão do que se experimenta, e, em terceira pessoa, a descrição dos objetos. Wittgenstein discorda e critica a separação entre sensações internas e manifestações externas. No texto de Investigações Filosóficas, ele apresenta o cotidiano: "Queremos compreender algo que já esteja diante de nossos olhos. Pois parecemos, em algum sentido, não compreender isto" (IF, § 89, p. 61). A linguagem faz parte das sensações que atingem os sujeitos, não são estados interiores antecedentes que se manifestam pela linguagem em segundo plano. Essa relação da linguagem com a experiência, assim entendida, aponta para a ideia de cotidiano como uma categoria filosófica.

É possível, no entanto, aderir a uma resposta: o cotidiano opera em nossas vidas, antes estrangeiro, agora em casa, retomada por uma compreensão encarnada da linguagem, ou seja, de uma linguagem em seu uso comum, que não precisa de suposições, de hiatos que a separem do mundo, mas esteja cotidianamente em casa, longe do exílio metafísico. É a força do acontecimento que deve ativar o funcionamento correto, a linguagem perfeita ao lado das instituições que nos definem como seres sociais, livres de jugos metafísicos, o que nos torna cada vez mais humanos:

Quando os filósofos usam a palavra - "saber," "ser", "objecto", "eu,, "proposição," "nome e - procuram captar a essência da coisa, devemo-nos sempre perguntar: na linguagem onde vive, esta palavra é de fato sempre assim usada?Nós reconduzimos as palavras do seu emprego metafísico ao seu emprego quotidiano (WITTGENSTEIN, 2002, §116, p.259).

Nesse sentido, o cotidiano como categoria filosófica em Wittgenstein começa justamente quando o sujeito se apossa dos sentidos da linguagem cotidiana, da prática linguística, portanto, é preciso reconsiderar o cotidiano, a fim de que este sirva de base para pensarmos a cultura e o homem contemporâneos, ou seja, 


\section{autêntica}

não se pode considerar unicamente o sujeito como ser individual, muito menos como o ideal de sociedade, em que se criam representações e uns sujeitos entram em correspondência com outros, porque grande parte da ação humana ocorre em uma comunidade que compreende a parte integrante de um "nós" e, como tal, o sujeito constitui a si mesmo.

A questão da linguagem é essencial para a compreensão do cotidiano como acontecimento produtor de experiências, e, consequentemente, produtor de sentidos; assim, recorrendo a Deleuze, o sentido é acoplado à expressão e é por meio dela que se engendra a significação, produzida pelo sujeito por meio da sua afetação6 pelo paradoxo do cotidiano. Neste sentido, Deleuze entende que: "O acontecimento pertence essencialmente à linguagem, ele mantém uma relação essencial com a linguagem; mas a linguagem é o que se diz das coisas" (1982, p.23). O improvável é organizado por meio da linguagem que também dá o seu sentido. E, sendo o sentido aquilo que é expresso, compreende-se o local de sua produção como algo entre o estado de coisas que é abalado e a linguagem. O sentido, é dessa forma, o próprio acontecimento expresso, é o resultado do que é produzido pelo rompimento do senso comum, das proposições metafísicas, obrigando a uma nova significação do possível, ou seja, o cotidiano como acontecimento abre a história, sugando tudo para que gire em torno de si.

A aula de filosofia, por exemplo, deve funcionar como um local de acontecimento que contribua para o sentido que se produz. Esta seria a nova epistemologia a ser adotada pelo professor do ensino médio. Porém, entre o acontecimento e sua expressão por meio da linguagem apresentam-se os enunciados que, segundo Deleuze, são distintos em sua proposição. O estado de coisas expressa-me mediante diferentes corpos e suas relações, e a designação, por sua vez, atua mediante a associação das palavras às imagens particulares. "O que conta, no momento, é que certas palavras na proposição, certas partículas linguísticas servem como formas vazias para a seleção de imagens em todo e qualquer caso" (DELEUZE, 1982, p.23).

Diante de um acontecimento, o movimento epistemológico para o ensino de filosofia transita por essa tentativa de buscar as particularidades para definir o estado de coisas que foi quebrado por esse acontecimento. Dessa epistemologia passa-se à manifestação e trata da relação da proposição do sujeito que fala e se expressa: "A manifestação se apresenta, pois, como um enunciado dos desejos e das crenças que correspondem à proposição" (DELEUZE, 1982, p.14). Deleuze apresenta desejos e crenças como relações causais e não como associações. Existe uma relação não-hierárquica com a designação e com a manifestação, e a proposição, apresenta, de acordo com Deleuze, a significação; esta seria a relação existente entre das palavras com os conceitos classificados como universais: "A significação se define por esta ordem de implicação conceitual em que a proposição considerada não intervém, senão como um elemento de uma 'demonstração', no sentido mais geral da palavra, seja como premissa, seja como conclusão" (DELEUZE, 1982, p.15).

A significação, desse modo, está sempre se relacionando com outras proposições das quais se conclui, ou, que torna possível a conclusão. Enquanto a designação se refere ao entendimento direto, a significação se refere ao indireto, em que o valor não é mais uma verdade absoluta, mas condição de verdade, é esta, segundo Deleuze, a possibilidade de tornar uma proposição verdadeira. Deleuze aponta o sentido como uma quarta dimensão da proposição: "Os estóicos a descobriram com o acontecimento: o sentido, é o expresso da proposição, este incorporal na superfície das coisas, entidade complexa e irredutível, acontecimento puro, que insiste ou subsiste na proposição" (DELEUZE, 1982, p. 20). O sentido, neste caso, é neutro e indiferente, tanto para o geral quanto para o particular.

6 Afetação aqui pode ser entendida como a apropriação dinâmica que o sujeito tem com a experiência. "Só há experiência quando há transação entre duas coisas que não são exteriores uma à outra, por exemplo, entre um organismo e o meio ambiente que o rodeia, em que cada um é afetado pelo outro e reage segundo sua constituição (QUÉRÉ, 2005, p.64). 


\section{autêntica}

Desse modo, entende-se o sentido como o expresso. Deleuze recorre a Husserl que entende o sentido como impossível de existir fora de sua expressão. Não se entenda aqui de uma circulação viciosa de relações complexas que se dão entre designação e manifestação, como na proposição, mas dois olhares, um voltado para as coisas e outro para as proposições. Aqui há uma superação do entendimento de Wittgenstein no Tractatus a respeito da proposição, que é o próprio estado de coisas.

Mas toda a argumentação que Wittgenstein elabora nas Investigações Filosóficas busca recuperar a importância da linguagem ordinária como forma de interação social e conhecimento, evoca o papel da comunidade na troca de conhecimento dentro de uma forma de vida. Este ponto é fundamental, visto que a linguagem ordinária não é apenas uma opção metodológica do autor, mas uma forma de elevar o 'ordinário' a uma categoria nova filosófica. As analogias e as metáforas, a que o autor recorre, só reforçam o fato de que a linguagem deve ser vista no uso e não em situações artificiais e criadas para se encaixar em certos modelos.

Dentro dessas analogias, talvez a mais importante e abrangente de todas seja o exemplo entre linguagem e uma cidade. É uma metáfora muito poderosa e sugestiva e pode ser útil para trazer algumas implicações para o estudo da língua. Diz Wittgenstein:

(E com quantas casas e ruas é que uma cidade começa a ser cidade)? A nossa linguagem pode ser vista como uma cidade antiga: um labirinto de travessas e largos, casas antigas e modernas e casas com reconstruções de diversas épocas; tudo isto rodeado de uma multiplicidade de novos bairros periféricos com ruas regulares e as casas todas uniformizadas (WITTGENSTEIN L., 2002, § 18).

E, dessa forma, tanto em Wittgenstein quanto em Deleuze, o sentido é o próprio acontecimento, e que se configura no cotidiano, o acontecimento, pode ser visualizado pela linguagem ordinária, pois é lá que ele se configura; o sentido expresso se mostra e se efetiva como categoria filosófica. Nesse caso, impõe-se a possibilidade de se falar em aplicabilidade e em empregabilidade do cotidiano como ponto de partida para a composição de uma epistemologia e de uma práxis pedagógica para o ensino de filosofia. Caso isso não ocorra, a reflexão que se propuser em sala de aula, acorrentada aos limites do pensamento sobre o cotidiano, não passará de um equívoco, que impedirá a sua análise filosófica bem como a superação de tal possibilidade.

\section{O COTIDIANO E ENSINO DE FILOSOFIA: MEDIAÇÕES}

O professor, como um agente mediador entre o cotidiano e o filosofar por meio da linguagem, constitui uma nova epistemologia e práxis pedagógica para o ensino de filosofia na contemporaneidade. Essa ideia revela outra concepção que aqui deve ser mencionada: a escola como uma instituição mediadora entre prática social e conhecimento científico. Saviani, 1989, por exemplo, entende que a práxis pedagógica não exaure a possibilidade de uma prática social global; ela atua como mediadora entre os sujeitos dessa práxis.

Dentro dessa perspectiva, a escola exerce a função mediadora entre conhecimentos sistematizados e a prática social, uma vez que, configurada para a transmissão de conhecimentos, cria competências e habilidades especificas para formar costumes, renovar teorias e convicções de que não é possível apropriar-se do cotidiano, condições tão necessárias para a vida em sociedade. Assim, a escola tem como escopo a mediação entre o estudante e o conhecimento sistematizado a que esse aluno deve acessar, a fim de que possa ter acessibilidade aos conhecimentos que estão fora da escola. 


\section{DOCENTE}

autêntica

Para Oliveira, 1992, é preciso aprofundar o significado dessa proposição de função da escola como mediadora; atuação que não deve ser compreendida pelo viés mecanicista e unilateral, como se a prática social fosse apenas uma ponte para que o sujeito acessasse a sua vida profissional em determinado período de seu existir:

A educação enquanto mediação no seio da prática social, precisa portanto, ser compreendida enquanto atividade que mantém um movimento recíproco dentro dessa prática mais ampla, durante todo o seu processo de produzir-se, além de ser também um momento (os anos de escolaridade) na vida de um indivíduo de determinada sociedade (OLIVEIRA, 1989, p.99).

A concepção de professor como mediador entre o cotidiano e o filosofar caracteriza-se fundamentalmente pela relação consciente do professor de filosofia com seu objeto de trabalho (texto filosófico) e pela necessidade de reflexão encarnada sobre o viés filosófico do cotidiano como o conjunto de acontecimentos, acontecimentos dotados de significação na vida do aluno. Segundo Alves: "Se o cotidiano pode ser tomado como um conjunto de acontecimentos, ele nos coloca em prontidão para a experiência filosófica na medida em que não podemos exercer o controle absoluto dos acontecimentos" (2016, p.4). E é essa a ideia: No descontrole dos acontecimentos, acontece o filosofar de maneira efetiva.

Quanto à relação que o professor de Filosofia deve exercer com o seu trabalho é importante ressaltar as recomendações dos Parâmetros Curriculares Nacionais do Ensino Médio, de 2006, relativas às competências e habilidades a serem desenvolvidas em filosofia:

\section{Representação e comunicação}

Ler textos filosóficos de modo significativo.

Ler, de modo filosófico, textos de diferentes estruturas e registros.

Elaborar por escrito o que foi apropriado de modo reflexivo.

Debater tomando uma posição, defendendo-a argumentativamente e mudando de posição face a argumentos mais consistentes.

\section{Investigação e compreensão}

Articular conhecimentos filosóficos e diferentes conteúdos e modos discursivos nas Ciências Naturais e Humanas, nas Artes e em outras produções culturais.

\section{Contextualização sociocultural}

Contextualizar conhecimentos filosóficos tanto no plano de sua origem específica, quanto em outros planos: pessoal-biográfico; o entorno sociopolítico, histórico e cultural; o horizonte da sociedade cientifico-tecnológica (Orientações aos PCNEM. Ciências Humanas e suas Tecnologias, p.64).

Esta citação é importante, porque coloca a ideia de uma nova epistemologia e práxis pedagógica do professor de Filosofia orientadas pela mediação entre o cotidiano e o filosofar?, como pressuposto básico em cursos de ensino médio. 


\section{CONCLUSÃO}

Fundamentados na pesquisa apresentada neste trabalho, é possível o entendimento sobre o que venha a ser a nova epistemologia e a nova práxis do professor de Filosofia no Ensino Médio na contemporaneidade: a sua fundamental contribuição como educador, para que haja mudança no ensino de filosofia em nosso país, e, principalmente, na escola pública. Que o professor possa entender o significado filosófico do cotidiano. Retomando à célebre passagem de Wittgenstein nas Investigações Filosóficas: "Queremos compreender algo que já esteja diante de nossos olhos, pois parecemos, em algum sentido, não compreender isto" (IF, $\S 89$, p. 61). Para que haja essa compreensão do cotidiano, como dispõe Wittgenstein, é necessário que se reencontre o verdadeiro significado da linguagem que se constitui no seu uso. $\mathrm{O}$ "isto" enunciado por Wittgenstein não é outra coisa senão o cotidiano que está difuso em todos os âmbitos da vida e que se encontra entranhado todas as nossas atitudes sociais em quaisquer contextos práticos da vida.

A urgência da ressignificação do cotidiano como categoria filosófica a ser aplicada em sala de aula, isto é, que ele seja uma nova epistemologia da práxis pedagógica do professor de filosofia, está na atitude desse professor diante dos acontecimentos.

Tais proposições nos encorajam a continuar lutando para que a Filosofia permaneça como disciplina no currículo escolar, mas só a teorização não basta como uma conclusão suficiente, como reivindica Alejandro Cerletti:

Sabemos também que uma parte importante da legitimidade que possa ter nosso campo deverá ser, em última instância, uma autolegitimação (somos conscientes de que são cada vez mais frequentes as tentativas de excluir progressivamente a filosofia dos currículos obrigatórios, substituí-las por outras disciplinas supostamente mais úteis ou práticas para o mundo de hoje) (2004, p. 22).

É preciso encarnar as novas formas de abordagem para que o aprendizado em filosofia seja de qualidade tal, que os estudantes possam, por meio da significação do cotidiano, que é em si mesma uma experiência filosófica, reconhecer a filosofia e sua importância sem que haja risco de perdê-la.

É urgente tal atitude, porque a valorização do cotidiano e seus acontecimentos e apenas essa conscientização em sua potencialidade pode lograr uma atuação legítima do papel da filosofia na vida do educando no Ensino Médio. Essa atitude poderá reconstruir, de maneira racional, o lugar da filosofia, assim como proporcionar a formação de indivíduos críticos, reflexivos, autônomos, constituindo categorias que devem ser colocadas em prática. Reportemo-nos à proposição inicial para um melhor entendimento:

1) $O$ ato de ensinar requer um exercício de reconsideração do cotidiano como categoria filosófica, isto é, a capacidade subjetiva de abertura para novas situações, novos mundos até então banidos do discurso epistemológico inerente à docência.

2) Este ponto diz respeito ao fato de deslocar os docentes do polo de suas certezas epistemológicas - as quais tiveram sua origem e fundamentação na metodologia de ensino não filosófica, que propõe a receita dogmática de percurso dos caminhos certos para uma aula de filosofia - para o polo do aluno do Ensino Médio que está indisponível para a Filosofia.

A filosofia, quando ensina por esse viés, atua sempre como possibilidade de criação, é espécie de aridez em que a experiência flui livremente e o diferente se põe em evidência. Se o professor de Filosofia suportar 


\section{autêntica}

a sensação de descontrole dos acontecimentos em sala de aula, pode agir de modo diferente, isto é, de maneira a produzir experiência filosófica.

A atuação mediadora do professor de Filosofia concebe o processo de criação, investigação e compreensão do processo de apropriação do conhecimento ordinário, a fim de resguardar o domínio crítico da possibilidade da descoberta, do espanto filosófico que se dá no acontecimento.

Não se trata de uma transmissão rígida do conhecimento elaborado, essa perspectiva de ensino de filosofia requer uma intervenção direta no campo de modelar a conduta dos alunos no campo da ética, da política, do gosto estético, na religião, além de outros conhecimentos, já está um tanto rechaçada. O que se propõe é o processo de mediação que é a tomada de posse do que se entende por ensinar filosofia: propiciar a autonomia intelectual.

Como nos propõem os Parâmetros Curriculares Nacionais do Ensino Médio de 2006 sobre as habilidades a serem desenvolvidas pelo ensino de filosofia: Representação e comunicação (...). Investigação e compreensão (...). Contextualização sociocultural (...) (p.64); podem ser essas as possibilidades que nos abram para a ressignificação do cotidiano nas aulas de filosofia, quando escolhermos o valor filosófico dos acontecimentos. 


\section{REFERÊNCIAS BIBLIOGRÁFICAS}

ALVES, Mauricio Silva. Reconsiderar as diferenças no cotidiano escolar: uma ontologia para o professor de

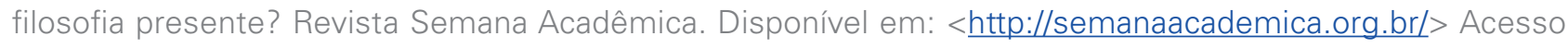
em 11 dez.2016.

BRASIL. Ministério da Educação. Secretaria de Educação Média e Tecnológica. Parâmetros Curriculares Nacionais: Ensino Médio. Brasília: MEC/SEMTEC, 2006.

BRASIL, Ministério da Educação. Secretaria de Educação Básica. OrientaçõesEducacionais Complementares aos Parâmetros Curriculares Nacionais. Ciências Humanas e suas Tecnologias. Brasília, DF, 2013. Disponível em:<<http://portal.mec.gov.br/seb/arquivos/pdf/CienciasHumanas.pdf>>. Acesso em: 10 out. 2016.

BRASIL, Governo Federal. Lei n. 11.684, de 02 de junho de 2008. Altera art. 36 da Lei 9394-96, Lei de Diretrizes e Bases da Educação Nacional. Brasília, DF, 2008.

CAMPANER, S. Filosofia: Ensinar e Aprender - São Paulo: Livraria Saraiva. 2012.

CAVELL, Stanley. Esta América Nova, Ainda Inabordável: Palestras a partir de Emerson e Wittgenstein. São Paulo: Editora 34, 1997.

CERLETTI, Alejandro. O ensino de Filosofia como problema filosófico.São Paulo: Autêntica, 2004.

CHAUÍ, M. Prefácio. In: MARÇAL, Jairo. (Org.). Antologia de textos filosóficos. Paraná: SEED, 2009.

CIAMPA, A.C. Identidade. In.: LANE, S.T. \& CODO, W. Org. Psicologia Social: O homem em movimento. $3^{\text {a }}$ ed. São Paulo: Brasiliense, 1985.

DELEUZE, Gilles. Lógica do Sentido. Perspectiva: São Paulo, SP, 1982.

HORN, G. B. Ensinar Filosofia: pressupostos teóricos e metodológicos. ljuí: Unijuí, 2009.

MORAES, M. C. Recuo da teoria. In.: MORAES, M.C.M. (Org.). Iluminismo às Avessas: Produção do conhecimento e políticas de formação Docente. Rio de Janeiro: DP\&A, 2003.

NÓVOA, A. Nada substitui um bom professor. In.: GATTI,B.A.(Org.). Por uma política nacional de formação de Professores, São Paulo: UNESP, 2013.

OLIVEIRA, B. A Prática social global como ponto de partida e de chegada para a prática educativa. IN.: OLIVEIRA, B. DUARTE, N. Socialização do saber escolar. 6ed. São Paulo, SP: Cortez: Autores Associados, 1992.

QUÉRÉ, Louis. Le caractere Impersonnel de l'expèrience. IN.: SIMPÓSIO DE COMUNICAÇÃO E EXPERIÊNCIA ESTÉTICA. 2, Belo Horizonte, MG. Fafich, UFMG, 2005.

SHULMAN, L.S. Knowledge and teaching: Fundations of the new reform 1987. IN.: SHULMAN, L.S. The wisdsom of pratice: essays on teaching and learning to teach. San Francisco, Jossey-Bass, 2004. 


\section{autêntica}

SHULMAN, L.SBThose who understand: Knowlwedge growth in teaching. Educacional, v 15, $n^{\circ} 2,1986$.

SHULMAN, L.S Communities of learners and communities of teachers. Jerusalém: Mandel Institute, 1997.

WITTGENSTEIN, L. Remarques Mêlées [no original Vermischte Bemerkungen]. Editado por G. H. von Wright. Tradução, apresentação e notas Gérard Granel e JeanPierre Cometti. Paris: Flammarion, 2002. Em português: Cultura e valor [do original Culture and Value]. Trad. Jorge Mendes. Lisboa: Edições 70, 2000.

WITTGENSTEIN L. Investigações Filosóficas. Lisboa: Fundação Calouste Gulberkian, 2002.

ZEICHNER, K. M. A formação Reflexiva de Professores: Ideias e Práticas. Lisboa: Educa, 1993.

ZEICHNER, K.; FLESSNER, R. Educando os professores para a Educação Crítica: Análise Internacional. Porto Alegre: Artmed, 2011. 